\title{
Practice and Exploration of Curriculum Ideological and Political Education in the Construction of Online Teaching Teams in Medical Universities
}

\author{
Ying Zhang1* Jie Wang2*, Kaifen Liang1, Bo Ling1, Zhongwei Zhang1, Guangbin Ye1, Xianjiu Liao"\#, \\ Xuebin Li'\# \\ ${ }^{1}$ Youjiang Medical University for Nationalities, Baise, China \\ ${ }^{2}$ Youjiang Medical University for Nationalities Affiliated Hospital, Baise, China \\ Email: "1xj2006910@163.com, "yyfylxb126@126.com
}

How to cite this paper: Zhang, Y., Wang, J., Liang, K. F., Ling, B., Zhang, Z. W., Ye, G. B., Liao, X. J., \& Li, X. B. (2021). Practice and Exploration of Curriculum Ideological and Political Education in the Construction of Online Teaching Teams in Medical Universities. Advances in Applied Sociology, 11, 194-199.

https://doi.org/10.4236/aasoci.2021.114015

Received: January 28, 2021

Accepted: April 19, 2021

Published: April 22, 2021

Copyright $\odot 2021$ by author(s) and Scientific Research Publishing Inc. This work is licensed under the Creative Commons Attribution International License (CC BY 4.0).

http://creativecommons.org/licenses/by/4.0/ (c) (i) Open Access

\begin{abstract}
Curriculum ideological and political education is the core idea and direction of the construction of online teaching teams in medical colleges and universities. With the development of information and intelligence, online teaching has become one of the important modes of education and teaching development in medical colleges and universities. The construction of online teaching teams plays a key role in the development of online teaching, with four core problems existing at present, including unclear teaching team goals, loose teaching team organization, imperfect teaching team systems and difficulties in achievement transformation. The solutions of the four core problems can be found by following the guidance of curriculum ideological and political education and the regularity of the teaching team development. Therefore, in this study, with the construction of online teaching teams in medical colleges and universities as an example, the role and value of curriculum ideological and political education in the construction of teaching team are analyzed deeply to provide the feasible direction of teaching reform in medical colleges and universities.
\end{abstract}

\section{Keywords}

Curriculum Ideological and Political Education, Medical Colleges and Universities, The Construction of Online Teaching Teams, Teaching Reform

\footnotetext{
*These authors contributed equally to this work.

\#Corresponding authors.
} 


\section{Introduction}

As is concerned with the development of Chinese medical and health services, medical colleges and universities undertake an important task of training morally-good doctors and medical workers who serve the people with healthcare, so as to promote the development of Chinese health industry (Zhang, 2019). Considering the characteristics of a great number of the basic and professional courses and the long time studying of these courses in the medical colleges and universities, the teaching method of traditional presentation is limited in the improvement of students' self-studying, reviews and innovation abilities (Ren, Shi, Hou, Zheng, \& Wang, 2020). The problem above could be solved effectively with the rise of online teaching mode. The effective application of online teaching lies in the construction of online teaching teams. The four problems, including unclear teaching team goals, loose teaching team organization, imperfect teaching team systems and difficulties in achievement transformation, appear due to the short time of the construction of online teaching teams in medical colleges and universities and the lack of experience (Zhang, Luo, Liang, Wang, $\mathrm{Wu}, \& \mathrm{Tan}, 2020)$. The solutions of the four core problems can be found by following the guidance of curriculum ideological and political education and the regularity of teaching team development.

\section{Analysis of the Current Situation of Online Teaching Team Construction}

1) Unclear team goals

In the construction of online teaching teams in medical colleges and universities, the team goals should first be planned wholly by academic leaders and formulated completely after fully considering the student cultivation, the teaching objectives, the discipline requirements and the scientific research development (Wang, Fei, Li, Chen, Liu, Hu, Mi, \& Mu, 2021). However, without full consideration of the teams' real situations and teachers' requirements at different levels, the goals are too broad or the unity of self-goals and team goals can't be realized. At the same time, the quantification and operability of the goals in the construction of online teaching teams require to be further specified and detailed to ensure the clarity and realizability of the goals.

2) Loose team organization

The loose organization of online teaching teams has always been a stumbling block to the teaching reform in medical colleges and universities (Wang, Qi, Meng, Wang, Li, Jia, Yang, Cui, \& Zou, 2020). First of all, the unreasonable allocation of personnel and the lack of the course leaders with senior professional titles and network technicians in the online teaching teams of medical colleges and universities have become the biggest difficulties. At the same time, the participation of team members is inactive, and some teachers as teaching team members neglect their obligations and responsibilities due to heavy curriculum tasks and the needs of their own development. With less cooperation between 
team members, teachers usually pay attention to the progress of their own teaching and scientific research, subjectively believing that their own development is the greatest contribution to the teams and completing the work that needs to be completed through mutual cooperation alone instead of actively cooperating with each other.

3) Imperfect teaching team systems

Perfect teaching team systems guarantee the healthy development of online teaching teams (Chen, 2018). In the construction of online teaching teams in medical colleges and universities, the teaching team systems should be formulated through discussion between team members but the problem of imperfect teaching team systems will appear due to the unfamiliarity of the front-line teachers, as the usual members of teaching teams, with the system establishment. The imperfections of systems are mainly reflected in the following aspects: First of all, the power and responsibility system of the teams is not perfect, and the rights and responsibilities among the members are not devolved to individuals, causing the team members to rely on self-awareness at work without constraint. Secondly, the lack of team reward and punishment system leads to the inactivity of team members and the idea of mess together, which requires paid rewards for promotion and work performance instead of verbal encouragement. The inexplicit work routines of the teams, for example, the inexplicit work plans and arrangements of the daily regular teaching meetings, teaching assessments and teaching improvement, cause the loose arrangements and the unsystematic team work.

4) Difficulties in achievement transformation

Online courses and first-class courses are the achievements of the online teaching teams. The online courses of medical colleges and universities mainly include theories, clinical skills and experimental skills, covering many disciplines such as medicine, pharmacy, nursing, clinical pathology and medical imaging. Although the achievements of online courses are rich, the effect is not ideal in terms of various evaluation factors such as the range of target audience, downloads and views, especially in hospitals, enterprises and foreign schools, where online courses are not frequently brought into use (Ma, Huang, Li, \& Zhu, 2020). The key reason is that the IUR (Industry-University-Research) mode has not been deeply performed, and hospitals, enterprises and foreign schools have not thoroughly understood the value and function of online courses.

\section{The Application of Curriculum Ideological and Political Education to Overcome the Difficulties in Online Teaching Team Construction}

1) Unified ideas and clear team goals

The unclear team goals originate from the disunity of team members' ideas. In the curriculum ideological and political education system, the unity of ideas is one of the basic contents (Huang, 2020). First of all, the cognition and needs of the online courses of the team teachers and technicians at different levels should 
be fully understood by referring to the method of full investigation in ideological and political education to investigate and research the team members and communicate with them. Secondly, the unified team goals should be formulated on the basis of different cognition and needs, so as to meet the overall honor of the teams and the needs of the team members' development. Relevant modification suggestions could be proposed after the unified goals are completed and returned to each member of the teams. After the modifications are completed, the unified team goals will be publicized for 7 days to ensure that the team goals will eventually be deeply rooted in mind and will be highly recognized and respected by all members.

2) Cohesion and reinforced team work

The fundamental reasons for the loose team organization are the lack of the cohesion and team spirit and the weak sense of team work. The application of resources of curriculum ideological and political education to strengthen the cohesion and team spirit is one of the effective solutions. In ideological and political education, the thematic education of the Red Army's Long March can be integrated to promote the patriotic feelings of the teams, enable the teams to foster lofty ideals and strengthen the determination of the team members to contribute to education ( $\mathrm{Li}, 2016)$. At the same time, in the education of the team members, the exploits of striving against COVID-19 can be learned in earnest, highlighting the pride of team members as teachers in medical colleges and universities and the great sense of mission of cultivating medical students (Gao, 2020). In all the work and meetings of the teams, the exploits of outstanding teachers in China can be learned, especially the dedication of the teachers to education, cultivating the selfless devotion and duty fulfillment of team members to contribute to the development of online teaching teams on their own (She, 2020).

3) Perfection of team system establishment in accordance with standards

The online teaching team systems of medical colleges and universities can be perfected on the basis of the establishment of the reward and punishment mechanism and training mechanism, in accordance with the national and provincial first-class curriculum team systems (Wang, Fan, Lai, \& Ren, 2020). In the reward and punishment mechanism, a quantitative system is implemented to classify the teams' achievements, honors and performance according to their contributions. The elimination system should be implemented for the team members with slowdowns and inactive participation, so as to ensure the overall efficiency and equity of the teams. In the training mechanism, a tutor-oriented training system can be carried out for team members to realize the guidance of young teachers by famous teachers with high professional titles, performing the role of helping and guiding. At the same time, all-round training aiming at the core teaching abilities of the team members, including online teaching plan preparation, teaching methods and teaching contents, can be adopted, where on-campus training and off-campus study combine to drive the enthusiasm of 
the team members as a whole and realize the sustainable development of the teaching teams.

4) Combination of IUR (Industry-University-Research) to enhance the transformation of team achievements

Online courses in medical colleges and universities have a strong advantage over the transformation of achievements, meeting the demand for talents and making key technology breakthroughs over product development and research in hospitals, enterprises and scientific research institutes. Therefore, the transformation of the achievements of online teaching teams in medical colleges and universities can be realized by responding to the needs of national ideological and political education and promoting the combination of IUR (Industry-University-Research). In the mode of IUR (Industry-University-Research), the teaching teams should take the initiative to establish partnership with hospitals, enterprises and scientific research institutes to promote the practicability of online courses and satisfy the demands of national industries by continually understanding, investigating and researching the key needs of hospitals and enterprises and involving in the preparation of online courses according to the needs. At the same time, the teaching teams can cooperate with front-line talents from hospitals, enterprises and scientific research institutes to create excellent courses, realizing advantageous course systems with rich theories and practices and realizing the transformation of achievements.

\section{Conclusion}

The establishment of online course systems in medical colleges and universities is the key direction of their education and teaching reforms. But the construction of online teaching teams requires to be improved in the establishment of online courses of medical colleges and universities. Therefore, with the curriculum ideological and political education as a breakthrough, this study aims at promoting the construction of online teaching teams in medical colleges and universities and realizing the qualitative breakthroughs in the construction of online courses and first-class courses, on the basis of the four core problems in the construction of online teaching teams in medical colleges and universities, including unclear team goals, loose team organization, imperfect team systems and difficulties in achievement transformation.

\section{Fund Program}

Undergraduate Teaching Reform Project of Guangxi Higher Education (Project No.: 2018JGZ132, 2019JGZ138, 2018JGA237); Innovation Project of Guangxi Postgraduate Education (Project No.: JGY2021214).

\section{Conflicts of Interest}

The authors declare no conflicts of interest regarding the publication of this paper. 


\section{References}

Chen, Y. (2018). Research on the Construction of MOOC Teaching Effectiveness of Ideological and Political Theory Course in Colleges and Universities in Yunnan Province. Kunming: Kunming University of Science and Technology.

Gao, F. (2020). Post-Epidemic Era: Digging into and Utilizing Ideological and Educational Resources Contained in “Anti-Epidemic”. Educational Exploration, No. 11, 62-65.

Huang, Z. Y. (2020). Reflection on Curriculum Ideological and Political Education in Medical Colleges and Universities. Science and Technology Consultation, 18, $178-180+183$.

Li, T. B. (2016). Promoting the Long March Spirit and Enhancing Cultural Confidence-Study on the Role of the Long March Spirit in Reshaping the Professional Qualities of University Teachers. Journal of Sichuan Provincial Correspondence Institute for Administrators, No. 4, 44-48.

Ma, D. X., Huang, N., Li, W. J., \& Zhu, R. F. (2020). Trial and Reflection on Online Teaching of Clinical Allergy. Chinese Journal of Allergy \& Clinical Immunology, 14, 500-504.

Ren, K., Shi, Y. M., Hou, J. C., Zheng, Z. H., \& Wang, L. X. (2020). Research on the Promotion of Medical Education Development to Teachers' Development in Medical Colleges and Universities. China New Telecommunications, 22, 220.

She, Y. (2020). Research on the Core Characteristics and Training Paths of Outstanding Teachers in Colleges and Universities-Based on the Text Analysis of the National Model Deeds of Teaching and Educating in Recent Nine Years. Writer's World, No. 24, 75-76.

Wang, L., Fei, C., Li, S. P., Chen, L. Q., Liu, J. J., Hu, R., Mi, H., \& Mu, Y. (2021). Exploration and Practice of Online Teaching of Clinical Hematology and Inspection. Health Vocational Education, 39, 41-43.

Wang, N., Qi, Y., Meng, L., Wang, C. Y., Li, M., Jia, W., Yang, L., Cui, X. B., \& Zou, H. (2020). Practical Study of Pure Online Teaching Mode for Experimental Course of Pathology. Health Vocational Education, 38, 92-94.

Wang, Y. C., Fan, H. Y., Lai, Y. W., \& Ren, K. (2020). Online Teaching of Curriculum Ideological and Political Education and Pharmacology under Epidemic Situation. Journal of Jilin Medical University, 41, 469-470.

Zhang, J. (2019). Research on the Coordinated Development of Innovation and Entrepreneurship Education and Ideological and Political Education in Medical Colleges and Universities in the New Era. Social Sciences Journal of Universities in Shanxi, 31, 86-89.

Zhang, L. F., Luo, Y. P., Liang, Y. L., Wang, J. Q., Wu, Y. F., \& Tan, J. Y. (2020). Exploration and Thinking of Performing Online Teaching of Medical Immunology by Using Multiple Platforms. Chinese Journal of Immunology, 36, 2346-2348. 